\title{
The impact of artificial intelligence on business: benefits and ethical challenges on customer level
}

\author{
Fadwa Bezzazi \\ School of Economics, Zhejiang University \\ 318 Liuhe Rd, Xihu, Hangzhou, Zhejiang, Chine \\ Tel: 86-571-8507-0000 E-mail: fadwa.bezzazi@gmail.com \\ Dongsheng Li, Zhantian Bi \\ School of Economics, Zhejiang University \\ 318 Liuhe Rd, Xihu, Hangzhou, Zhejiang, Chine
}

\begin{abstract}
Artificial intelligence is nowadays transforming the industries all around the world. Many businesses are confused whether investing in that new technology and taking a part of this race or taking the risk of losing a competitive advantage in the market. According to data, artificial intelligence AI will lead to an estimated $\$ 15.7$ trillion, which is $26 \%$ increase in global GDP by 2030. This study shows the impact of AI on businesses especially the benefits and ethical challenges by analyzing data collected from a sample of more than 100 random people.
\end{abstract}

Keywords: Artificial Intelligence, business, consumer behavior, marketing strategy, AI investment, ethics

DOI: $10.7176 / \mathrm{JMCR} / 81-06$

Publication date:August $31^{\text {st }} 2021$

\section{Introduction}

AI (Artificial Intelligence) is the science of getting machines to mimic the behavior and intelligence of human. It's used in a wide range of fields including: Healthcare, Robotics, Business analytics, Marketing, object detection, natural language processing, expert systems and so many more. AI is interconnected with machine learning and deep learning which are two different subset of AI, machine learning helps machine make decisions by feeding them data while deep learning uses neural networks to solve complex problems.

AI could be the 21th century's new biggest industry. All the world's tech giant companies (Alibaba, Amazon, Apple, IBM, Tencent...) are in a race to provide the next level products and services to their customers and become the world's leaders in artificial intelligence AI.

Not only big companies but even small businesses now are using technologies of AI by automating their systems to reduce the working time, scheduling management, errors and enhance the productivity and efficiency so they can grow fast.

A survey made in 2018 conducted by Vistage regarding the role of AI for small businesses revealed that $13.6 \%$ of small-to-medium businesses are currently using AI technologies to improve their business operations and customer engagement. Another statistic made by Semrush says that $75 \%$ of executives fear going out of business within 5 years if they don't scale AI.

A survey made in 2018 conducted by Vistage regarding the role of AI for small businesses revealed that $13.6 \%$ of small-to-medium businesses are currently using AI technologies to improve their business operations and customer engagement. Another statistic made by Semrush says that $75 \%$ of executives fear going out of business within 5 years if they don't scale AI.

This work is a study on the impact factors of AI on businesses. Since AI is a must introduce in different departments in business, should all businesses use it to exist on the market and what are the limits of this technology while implementation without losing customers trust. 


\section{Background:}

According to Britannica the definition of AI is the ability of a digital computer or computer-controlled robot to perform task commonly associated with intelligent beings. Data shows that the use of AI in many sectors of business in the world has grown by $270 \%$ over the last four years with $90 \%$ of leading businesses that have ongoing investment in AI technologies.

Artificial intelligence is no longer a mysterious topic and less confused with sci-fi (science-fiction) nowadays. All futurists, all numbers showed that the future is related to the AI not only in business but in many other fields; medical, business, security, agriculture, sport and activities, manufacturing and production, virtual assistant...

In this study we are interested in the two giant economies China and the united state by analyzing the ecosystem of each one and they are investing billion dollars to become the world's leader in AI.

\subsection{AI in China}

Since 2012 the President Xi Jinping has made artificial intelligence the main focus of China's innovation and high-tech development. Under the leadership of Xi Jinping many policies were released on various aspects from military applications to manufacturing, healthcare, ecological preservation. Later the Chinese government has launched the Next Generation Artificial Intelligence Development Plan in order to build China's AI ecosystem, promising policy support, central coordination and investments that are slated to cross the $150 \$$ billion mark by 2030

The main aim of these investments is to generate 1 trillion Yuan (160\$ billion) of annual revenues, with related industries crossing 10 trillion Yuan (1.6trillion\$) in annual sales, by the end of the current decade.

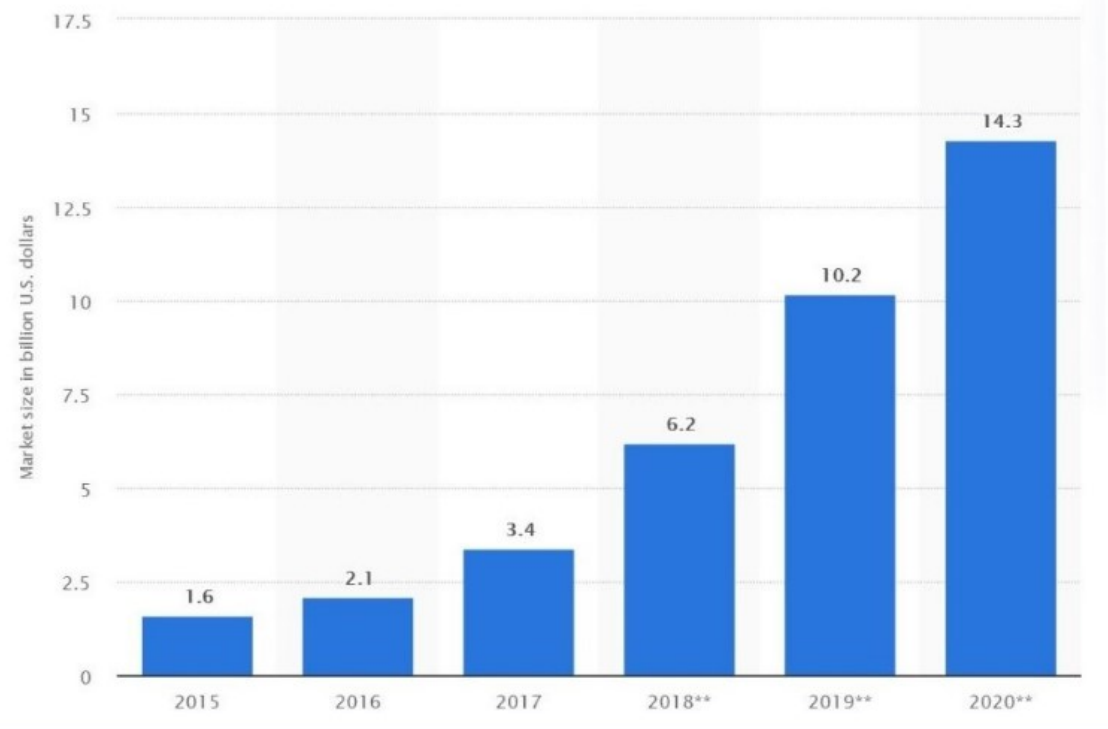

\subsection{AI in the United States:}

The secretary of State Antony J. BLINKEN stated at the NSCAI Global Emerging Technology Summit in Washington, D.C. on the 13th of July "A global technology revolution is now underway. The world's leading powers are racing to develop and deploy new technologies like artificial intelligence and quantum computing that could shape everything about our lives - from where we get energy, to how we do our jobs, to how wars are fought. We want America to maintain our scientific and technological edge, because it's critical to us thriving in the 21 st century economy."

AI is everywhere in the daily life of Americans it provides great benefits to the social life in many aspects such as precision medicine, education, security, public welfare. AI impacts the daily life of everyone and led to transformative advances including mapping technologies, voice-assistance, hand writing recognition for mail delivery. 


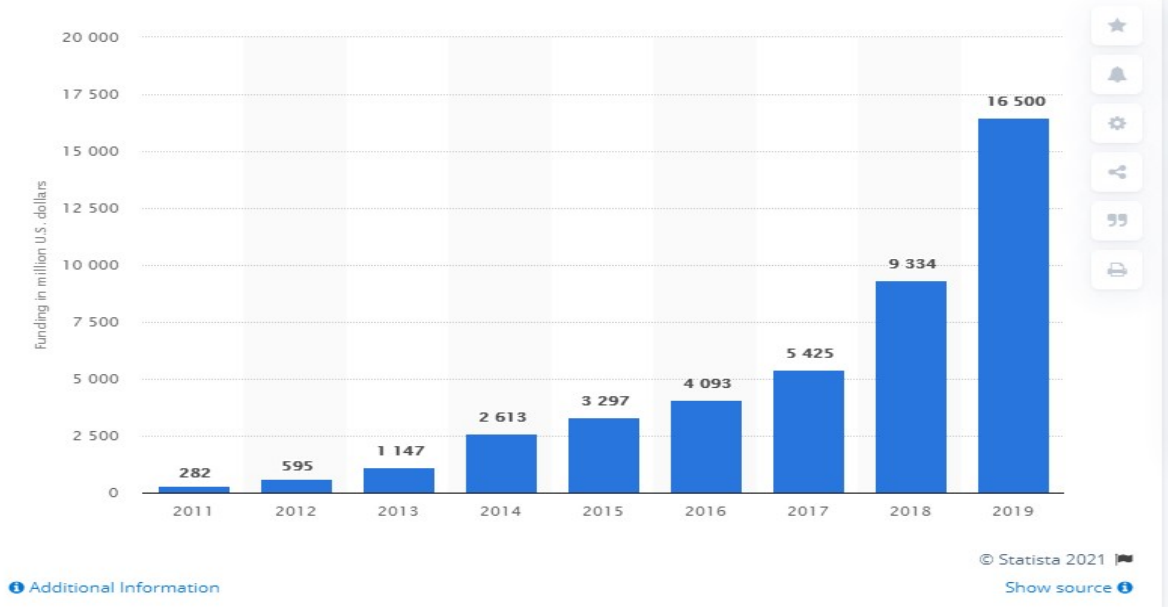

\section{Literature review:}

Starting from the Dartmouth workshop artificial intelligence AI is defined as the problem of "making a machine behaves in ways that would be termed intelligent if a human being behaved like this" (McCarthy et al., 1955) and this includes many fields, e.g., machine learning, computer vision, speech recognition, and natural language processing; (Russell \& Norvig, 2016). During the last fifty years AI has reshape the ways of doing business (Schneider \& Leyer, 2019). By generating and using the information, AI helps making decision, and thus influencing trade and management practices for many sides which help to provide better sustainable products or services.

The relation between human intelligence and artificial technologies represented by algorithms, that support managers to make the best decisions, and the ability to generate a standard management system from a large number of data, connection and interaction.

Some researchers (Huang \& Rust, 2018) have decided to study the impact of AI on consumers, firms, and stakeholders in an automated and connected world. This investment, according to (IDC, 2019) is expected to increase to $\$ 77.6$ billion in 2022 . Towards encourage extra advancements in research on business applications of AI.

While other researchers, have focused on the application of artificial neural network in business, (Tkac and Verner( 2016) or to the systematic mapping of the diffusion stages of business intelligence and analytics implementation( Corte-Real, Ruivo, and Oliveira(2014)).

\section{Methodology:}

The research represents an exploratory study based on a survey of a sample of 100 people taken randomly. The data collected is explained in graphs and tables using Excel. For this study the data used is primary data. The collected primary data researcher surveys 100 e-commerce users both female and male that go shopping frequently from online platforms. For the secondary collected data is from articles, publications, books and websites.

\section{Benefits of AI for consumers:}

The AI market was valued at $\$ 16.06$ billion in 2017 and could reach as expected \$190.61 billion by 2025 (Markets \& Markets, 2018). In today's economy, AI is the most important new technology that captured the interest of most researchers and companies. That leads us to go deeply into the researches about benefits of the $\mathrm{AI}$ in many sectors especially in business.

Firstly we have to aware that AI became a part of our daily life. This study highlights some benefits of AI shown in recent article and publications. Talking about business is talking about business management (e.g. smart email, categorization, voice to text features, security surveillance, automated responders and online customer support, sales and business forecasting...), Also e-commerce ( e.g. personalization services, fraud detection and prevention for online transactions, smart searches and relevance features, product recommendations and purchase predictions ...) and finally AI in marketing (e.g. social semantic and sentiment analysis, automated web 
design, customer segmentation, predictive customer service...)

In their research, (V. Kumar, Ramachandran \& B. Kumar, 2020) studied the influence of AI on marketing and evoke the major benefits of this new-age technology and illustrating by examples from our daily used platforms. The access to more detailed and real-time data of customers and devices firms affirmed that they can improve their experiences and manage the needs of their existing database of customers. Thus AI allows firms to deliver right content to the right customer at the right time like American Express that uses algorithms and data analytics for fraud detection in real-time (V. Kumar, Ramachandran \& B. Kumar, 2020).

AI can help marketers for a better prediction of future trends using advanced data mining techniques, which help the firms to anticipate the upcoming trends and craft responses (like changing the delivery strategy.). For instance, Netflix uses AI to analyze its audience data and according to the interest of the customers, Netflix can predict what people want to watch. With its strong data analytics capabilities, today, Netflix is able to invest in the creation of many episodes and seasons of new show rather than using just pilot as other production companies (Marr, 2018).

AI helps also to have a great traceability of products. In China, Alibaba developed an internal blockchain system in order to track product authenticity via supply chain, while in Europe, Carrefour can ensures the traceability of its products and their origin, like how each animal was reared, with information about the farmer, quality label, the location of slaughter...all this is possible using the blockchain technology (Carrefour, 2018). And so many more examples of big companies that are using AI in their business speed their development and line up with the emergence of digital innovation in business.

\section{Ethical challenges:}

Stephen Hawking, the physicist, believes that AI could be miraculous or catastrophic, and affirmed that AI could be "the last event in our history unless we learn how to avoid the risks" (Time, 2018).

AI technology is promising scientific achievements, efficiency and freedom, but at the same time, AI is foreshadowing human dependence, obsolescence and passivity. Due to this paradox of AI we have many ethical challenges associated to AI-enabled products. That's why urgent call for research on AI ethics was made to professional organizations (www.aies-conference.com).

Nowadays, consumers have paradoxical feelings toward AI technology; they like the shining side of AI that helps to save time, money and get more capabilities but in another hand are worried about the dark side of such a new mysterious technology (Mick \& Fournier, 1998). While the widespread adoption of AI-enabled products depends on the consumer trust, the consumer trust is related to how the key ethical concerns are managed such as (cyber security, privacy, AI biases...). Prior research proved that when it comes to ethics, not all AI products are the same ( Bostrom \& Yudkowsky, 2014).

The use of technological products showed in various studies that it has negative effects on consumers; such as aggressive behavior, techno-stress or cyber addiction (Samaha \& Hawi, 2016). Which lead us to believe that, technological products have moral and ethical issues.

In this study we will focus on the consumer level ethical issues. We have mentioned through our research and investigation with a sample of 100 people that firms using AI technologies are facing two major ethical challenges; the responsibility of protecting the consumer privacy and ensuring the security of consumer personal data.

We asked people if they are aware that some famous platforms use AI to provide very good service the answer as its shown below in graph1 was that more than $86 \%$ affirmed it. While when we asked them if they agree with that, the percentage was reduced to $61 \%$, which means that there is a lack of trust and many people are worried about their privacy and the security of their information.

13 - Do you know that Al collects data to offer a better service? 101 réponses
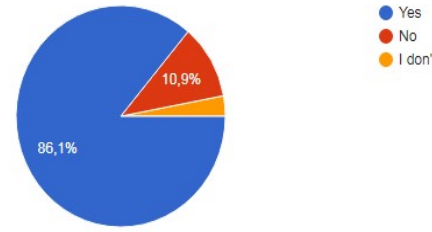

- Idon'tknow
14 - Do you agree that e-commerce platforms use your data to provide adjusted services to

your needs?

101 réponses

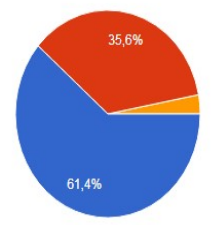

- No

I don't know 
We can't ignore the importance of privacy when it comes to ethic issues in the age of big data and AI technologies. Privacy is defined as the right to control your information by yourself (DesJardins, 2014); we talk about violation of privacy when your collected data is used without your permission and consent by third parties. Firms including AI is their business strategies have a big responsibility to first gain the trust of their clients then should keep this trust as long as they are in the market, once the trust is broken it may affect the whole value of the firm. Also they need to provide a clear and easy to understand communication about the privacy rules. Privacy policies should be accessible from the clients, with a guideline how the data is collected used and protected. In addition companies have to give a rewards or additional services to people who share its information and trusted the company like free services, customized offers.... And finally companies should give more lead to customers over the management of their data.

\section{Limitations of the study:}

Sample size: our sample evolves 200 people with this size it's hard to have a clear idea about the case.

Lack of documentation: The topic is large and new many databases don't give open access to their articles.

Online questionnaire: People answering online are not completely trustful since we can't see the one who answered it. People chosen should respond some criteria which limits the number of participants.

The CEO of Google "Sundar Pichai" announced that "AI is among the most important things that humans are actually working on. It is more profound than electricity or fire" (Clifford, 2018). However, some people have another opinion about this AI. The main concerns for them is the undefined danger, such as taking the control over humans and destroying them, human becoming useless and week compared to machines and robots.

Even Elon musk, the founder of SpaceX and CEO of Tesla Motors and also called "Humanity's biggest existential threat"'( Times, 2018). Many famous researchers believe that AI can be a miraculous and catastrophic depends on how we use it and how we avoid risks.

\section{Discussion and conclusion:}

Today's marketplace is demanding the implication of AI-enabled product which is beneficial for companies to grow fast and compete efficiently in the market. However the use of AI has two sides one magical and one might be a tragedy for humanity. Researchers are mixed between two scenarios and still ask for more research in many fields of AI. In this study we focused on the ethical benefits and challenges of the AI-enabled products, we addressed for that a survey asking more than 100 people taken randomly but all of them are connected to new technologies, we asked them several questions about how they feel about e-commerce in general and also what do they think about new technologies and big platforms using AI products. The sample is made of $27 \%$ male and $74 \%$ of women, mostly aged between 26 and 35 years old as shown is graph3.
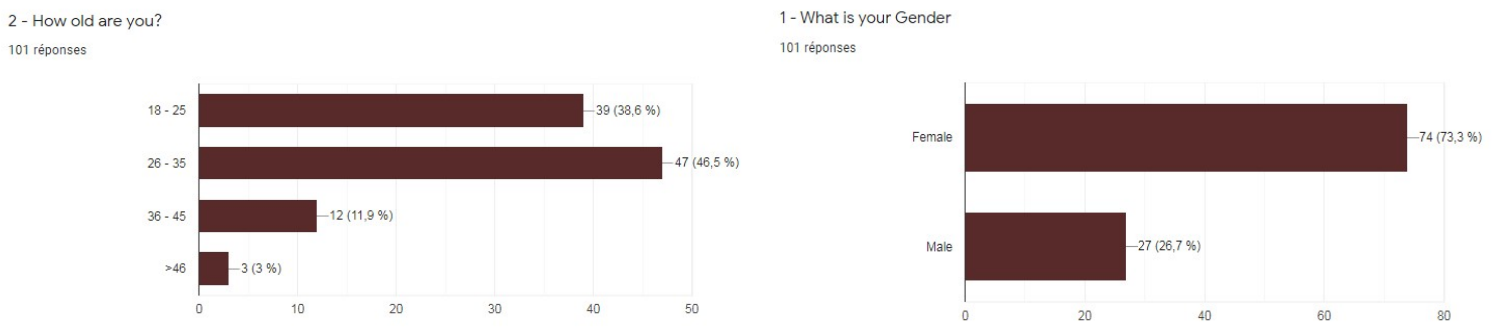

Graph3: Distribution of genre and age of participants in the survey

Most of the participants are satisfied with the online shopping and services and know the big companies that has AI-enabled products as shown in Graph4 
5 - Are you satisfied of online shopping and services? 101 réponses
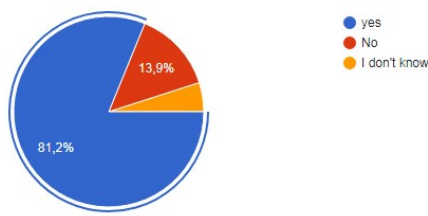

Graph4: Distribution of answer on Q 5 \& 6 of the survey

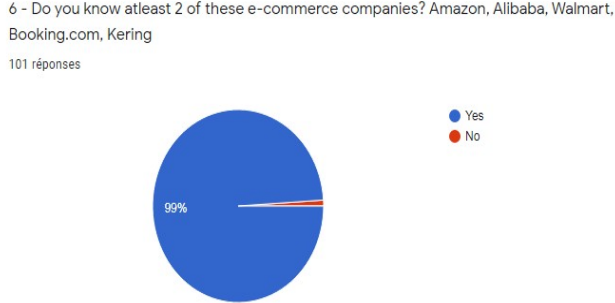
security they become more reticent and less cooperating but if they have benefices out of this risk they show more tolerance as showed in Graph 2 when we suggest adjusted services we have $61 \%$ that accepted with is not ignorable percentage. More than the half is willing to share their data for more beneficial offers.

$\mathrm{AI}$ is no doubt the future trends in business, however there are still so much work to be done from researchers and companies owner to develop this new technologies to educate people and lead to a trustworthy established basis to encourage people to adopt this new facilities and capabilities and allow firms to get more data and develop more services and achievements in near future also solve many problems in many areas like healthcare, robotics, management and business.

\section{References}

McCarthy, J., Minsky, M. L, Rochester, N., \& Shannon, C. E. (2006).A proposal for the Darmouth summer research project on artificial intelligence, august 31, 1955. AI Magazine, 27(4), 12-12. https://doi.org/10.1609/aimag.v27i4.1904.

Schneider, S., \&Leyer, M. (2019). Me or information technology Adoption of artificial intelligence in the delegation of personal strategic decisions. Managerial and decisions Economics, 40(3), $223-231$. https://doi.org/10.1002/mde.2982.

Russell, S. J, \& Norvig, P. (2016). Artificial Intelligence: A modern approach (3rd ed.). Essex: Pearson.

Huang, M. H, \& Rust, R. T. (2018). Artificial intelligence in service. Journal of Service Research, 21(2), $155-172$.

IDC, (2019). Retrieved from https://www.idc.com/getdoc.jsp container Id=pr U S44291818 on 18 January 2019.

Tkac, M., \& Verner, R. (2016). Artificial neural networks in business: Two decades of research. Applied Soft Computing, 38, 788-804.

V. Kumar, Ramachandran \& B. Kumar, 2020. Influence of new-age technologies on marketing: A research agenda. Journal of business research, Elsevier. 0148-2963.

Corte-Real, N., Ruivo, P., \& Oliveira, T. (2014). The diffusion stages of business intelligence \& analytics (BI\&A): A systematic mapping study. Procedia Technology, 16, 172-179.

Marr, B. (2018). 27Incredible examples of AI and machine learning in practice. Retrieved from<https://www.forbes.com/sites/bernardmarr/2018/04/30/27- incredible-examples-of-ai-and-machinelearning-in-practice/\#19cc0ae87502>.

Time (2018). What seven of the world's smartest people think about artificial intelligence. Available at http://time.com/4278790/smart-people-ai/

Mick, D. G., \& Fournier, S. (1998). Paradoxes of technology: Consumer cognizance, emotions, and coping strategies. Journal of Consumer Research, 25(2), 123-143.

Bostrom, N., \& Yudkowsky, E. (2014). The ethics of artificial intelligence. In K. Frankish, \& W. M. Ramsey (Eds.). The Cambridge handbook of artificial intelligence. Cambridge University Press

Samaha, M., \& Hawi, N. S. (2016). Relationships among smartphone addiction, stress, academic performance, and satisfaction with life. Computers in Human Behavior, 57, 321-325.

Markets and Markets (2018). Artificial Intelligence Market by Offering, technology, enduser industry, and 
geography - Global forecast to 2025. Available at:

https://www.marketsandmarkets.com/Market-Reports/artificial-intelligence-market-74851580.html

DesJardins, J. (2014). An introduction to business ethics. New York, NY: McGraw-Hill/ Irwin 10020.

Clifford, C. (2018), Google CEO: A.I is more importance than fire or electricity. Available at: https://www.cnbc.com/2018/02/01/google-ceo-sundar-pichai-ai-is-moreimportant-than-fire-electricity.html

(accessed December 20, 2018). 